\title{
Semantic Web/LD at a Crossroads: Into the Garbage Can or To Theory?
}

\author{
Abraham Bernstein \\ University of Zurich \\ bernstein@ifi.uzh.ch
}

From Greek mythology (abbreviated from the Wikipedia):

Scylla and Charybdis were mythical sea monsters noted by Homer. Scylla was rationalized as a rock shoal (described as a six-headed sea monster) and Charybdis was a whirlpool. They were regarded as a sea hazard located close enough to each other that they posed an inescapable threat to passing sailors; avoiding Charybdis meant passing too close to Scylla and vice versa. According to Homer, Odysseus was forced to choose which monster to confront while passing through the strait...

Since its inception Semantic Web research projects have tried to sail the strait between the Scylla of overly theoretical irrelevance and the Charybdis of nonscientific applied projects.

Like Odysseus the Semantic Web community was wooed by the neatness of theoretical explorations of knowledge representation methods that endanger to crash the community into the Scylla the rock of irrelevance.

On the other side the maelstrom of Charybdis attracts the community as it tries to fulfill the next vision of the next web thereby loosing its scientific identity.

In this talk I will discuss and exemplify the strengths, weaknesses, opportunities, and pitfalls (or threats) of each of these extremes. I will use this analysis as a basis for to explore some possible strategies to navigate the potentially stormy seas of the Semantic Web community's future. 